\title{
GC-MS Analysis of Raw and Roasted Seeds of Chrysophyllum Albidum, a Medicinal Plant Used for the Treatment of Tuberculosis
}

\author{
Morufu Adisa Ademoye ${ }^{1}$, Labunmi Lajide ${ }^{2}$, Bodunde Joseph Owolabi ${ }^{3}$, Catherine Chizoba Onubogu ${ }^{4}$ \\ ${ }^{1}$ Chemistry Department, School of Sciences, Federal University of Technology, Akure, Nigeria \\ ${ }^{2}$ Chemistry Department, School of Sciences, Federal University of Technology, Akure, Nigeria \\ ${ }^{3}$ Chemistry Department, School of Sciences, Federal University of Technology, Akure, Nigeria \\ ${ }^{4}$ Centre for Tuberculosis Research, Nigerian Institute of Medical Research, Yaba, Nigeria
}

\begin{abstract}
Tuberculosis is a multi-systematic disease with myriad presentations and manifestations and is the most common cause of infectious disease-related mortality worldwide. The disease is treated with the roasted cotyledonous part of Chrysophyllum albidum seeds by traditional practitioners in Ogun state, Nigeria. The phytoconstituents of the hexane fraction and the hexane extracts of the roasted seeds at $50^{\circ} \mathrm{C}, 100^{\circ} \mathrm{C}$ and $120^{\circ} \mathrm{C}$ were investigated using GC-MS analysis. The results showed the hexane fraction of the raw seeds contained $92.71 \%$ by proportion of esters of long chain fatty acids. The hexane extract of roasted seeds $\left(50^{\circ} \mathrm{C}\right)$ contained $68.69 \%$ of long chain fatty acids, hexane extract of roasted seeds $\left(100^{\circ} \mathrm{C}\right)$ contained $74.54 \%$ while the hexane extract of roasted seeds $\left(120^{\circ} \mathrm{C}\right)$ contained $91.65 \%$.The traditional method of application of roasted seeds instead of raw seeds in treating tuberculosis enhances the availability of free fatty acids. The main fatty acids content at $120^{\circ} \mathrm{C}$ are Hexadecanoic acid and 9, 12Octadecadienoic acid. Fatty acids had been reported to be toxic to Mycobacterium tuberculosis. Thus the efficacy of the treating of tuberculosis with the roasted seeds of Chrysophyllum albidum is due to the presence of hexadecanoic acid and 9,12-Octadecadienoic acid which could work together or work synergistically with other antimicrobial effectors to bring about macrophage-mediated killing of the pathogen.
\end{abstract}

Keywords: Tuberculosis, antimicrobial, phytoconstituents.

\section{Introduction}

Tuberculosis is an airborne infectious disease that primarily affects the lungs. It can affect other parts of the body. The causative agent of tuberculosis is Mycobacterium tuberculosis. The bacterium infects macrophages and it adapts to the hostile intracellular milieu of this cell by exploiting the plasticity of its central carbon metabolism machinery (Mehrotra et al, 2014). Infection with Mycobacterium tuberculosis (MTB) is accompanied by an intense local inflammatory response which may be critical to the pathogenesis of tuberculosis (Toossi, 2000). The Mycobacterium tuberculosis possesses a distinct cell wall which is necessary for the bacteria's survival because it contains a fatty acid called mycolic acid which provides a strong lipid barrier (Cantrell, 2013). The ability of the organism to remain dormant or persistent within host cells for many years with the potential to be activated allows the bacterium to escape the immune system of the host (Meena and Rajini, 2010). Survival mechanisms of the bacterium include prevention of phago-lysosome fusion (Pieters, 2008), prevention of cell acidification (Queval et al, 2017) and protection against reactive nitrogen intermediates (RNI) (Rousseau et al, 2004). Although drug-sensitive TB is a treatable disease, the current standard treatment requires 6-8 months of a multi-drug regimen to achieve relapse-free cure. This long course of 
treatment is often associated with toxicity, poor adherence and development of drug resistance (Lee, 2017). The emergence of extensive drugresistant tuberculosis (XDR-TB) has significantly threatened to jeopardize global efforts to control TB, especially in HIV endemic regions (Prasad et al, 2017). There is need for anti-tuberculosis agents that could help in adjunct therapy to bring about shortening the treatment regimen, minimizing the side effects of the current antitubercular drugs and effective against antibiotic resistant strains. In laboratory settings, plant extracts have been shown to have a variety of pharmacological effects, including antiinflammatory, vasodilatory, antimicrobial, anticonvulsant, sedative and antipyretic effects (WHO, 2002).

Chrysophyllum albidum, African star apple, belongs to the plant family Sapotaceae. The plant is a lowland rain forest tree species that grows up to 25 to $37 \mathrm{~m}$ in height at maturity with a girth varying from 1.5 to $2 \mathrm{~m}$ (Oboh et al, 2009). The plant extracts possesses hepatoprotective activity (Adebayo et al, 2011).The ethanol root bark extract showed anti-fertility activity (Onyeka et al, 2012). The seeds of the plant could remove metal ions from aqueous solution (Oboh et al, 2009). The roots, barks and leaves of $\mathrm{C}$. albidum is/are widely used as an application to sprains, bruises and wounds in southern Nigeria (Olorunnisola et al, 2008; Mac Donald et al, 2014). The bark is used for the treatment of yellow fever and malaria. The root and stem barks are used in urinary related infections (Florence and Adiaha, 2015). The leaf is used as an emollient and for the treatment of skin eruption, stomacheache and diarrhea (Adisa, 2000) and for cancer remedy in Cuba (Mac Donald et al, 2014). Treatment of diabetic rats with ethanolic extract of the $\mathrm{C}$. albidum seed cotyledon lowered blood glucose level (Olorunnisola et al, 2008). The methanolic extract and fractions of C. albidum possessed antiplasmodial effect (Adewoye et al, 2010).The cotyledons from the seeds of Chrysophyllum albidum are used as ointments in the treatment of vaginal and dermatological infections in Western Nigeria. The cotyledonous part of the seeds of
Chrysophyllum albidum are roasted and put in honey by traditional practitioners in Ogun state part of Nigeria for the treatment of tuberculosis.

The aim of this study is to scientifically validate the therapeutic claim of the seeds by conducting antimycobacterium tuberculosis test and using GC-MS to investigate possible antitubercular agents present in the seeds.

\section{Materials and Methods}

\section{Extraction and Fractionation of Chrysophyllum Albidum Seeds}

The air-dried cotyledonous part of the seeds of C. albidum were grounded into powder. $60 \mathrm{~g}$ of the powder were put in $200 \mathrm{mls}$ of $80 \%$ ethanol solution and shaken intermittently at room temperature for 72 hours. Then, the mixture was filtered and the filterate was evaporated using an oven evaporator set at $42.5^{\circ} \mathrm{C}$. The $2.9 \mathrm{~g}$ yield of the ethanolic extract was subjected to sequential liquid partitioning to give $1.94 \mathrm{~g}$ of butanol fraction, $0.48 \mathrm{~g}$ of ethylacetate fraction and $0.01 \mathrm{~g}$ of hexane fraction. The fractions were tested for anti-mycobacterium tuberculosis.

\section{Preparation of Samples of Roasted seeds of Chrysophyllum albidum}

In line with the folklore usage of the seeds of Chrysophyllum albidum in treating tuberculosis infection, 100 seeds of the plant were put in a closed crucible and heated for 30 minutes at $50^{\circ}$ $\mathrm{C}, 100^{\circ} \mathrm{C}$ and $120^{\circ} \mathrm{C}$ separately. The cotyledonous part of the seeds were removed from their shells after heating and were grounded to powder for hexane extraction at room temperature. The yields were $0.13 \mathrm{~g}, 0.15 \mathrm{~g}$ and $0.16 \mathrm{~g}$ of hexane extracts respectively for the temperatures. Various concentrations of the $50^{\circ} \mathrm{C}$ and the $120^{\circ} \mathrm{C}$ were subjected to antimycobacterium tuberculosis test.

\section{The Test Organisms}

The reference Mycobacterium tuberculosis strain $\mathrm{H}_{37} \mathrm{R}_{\mathrm{V}}$ labeled $\mathrm{PT}_{12}$ and the local isolates labeled $\mathrm{PT}_{10}$ were used. The local isolates were isolated from TB patients using standard methods (Salami and Oluboye, 2002). The organisms were sub- 
cultured in Middle Brook 7H9 broth supplemented with $\mathrm{OADC}$ at $37^{\circ} \mathrm{C}$ for 21-28 days and were confirmed acid fast gram positive bacillus using Ziehl Nelson stain.

\section{Anti-mycobacterium Tuberculosis Test}

The anti-mycobacterium tuberculosis test was done using proportion method. $5 \mathrm{mls}$ of the filtered extract solutions (DMSO as solvent) were added to $15 \mathrm{mls}$ of the homogenized egg $\mathrm{LJ}$ media to arrive at various concentrations ranging from 50 $\mathrm{mg} / \mathrm{ml}$ to $0.5 \mathrm{mg} / \mathrm{ml}$. Each $20 \mathrm{mls}$ medium was divided into $10 \mathrm{mls}$ in universal containers. Standard drugs, isoniazid and rifampicin, at $0.2 \mu \mathrm{g} / \mathrm{ml}$ and $0.4 \mu \mathrm{g} / \mathrm{ml}$ respectively, were added to LJ media accordingly. The media were slanted to form slopes. The LJ slopes without extracts and drugs were used as control. The slopes were insipissated at $85^{\circ} \mathrm{C}$ for 45 minutes, cooled and stored in a refrigerator at $4^{\mathrm{O}}$ C. Sterility and viability check were carried out before inoculation.

\section{Inoculation of slopes with the bacteria}

Bacterial dilutions $10^{-5} \mathrm{mg} / \mathrm{ml}$ and $10^{-3} \mathrm{mg} / \mathrm{ml}$ were prepared for inoculation. $0.1 \mathrm{ml}$ of the chosen bacterial dilutions was inoculated into all the labelled LJ slopes (Adeleye et al, 2008). The universal containers were loosely closed with caps to allow evaporation and were incubated at $37^{\circ} \mathrm{C}$. The specimens were checked on the $7^{\text {th }}, 14^{\text {th }}$, and $21^{\text {st }}$ days to ensure no contaminations. Readings were done on the $28^{\text {th }}$ day.

\section{Nitrate Reduction Test}

Nitrate reduction test was performed on all the slopes after 28 days. This involved addition of $2 \mathrm{mls}$ Nitrate Substrate Broth, incubation at $37^{\circ} \mathrm{C}$ for 2 hours, addition of 1 drop of $50 \%$ hydrochloric acid, 2 drops of AFB Nitrate Reagent A (sulfanilamide, $0.2 \%$ ) , 2 drops of AFB Nitrate Reagent B (Naphthylethylenediamine Dihydrochloride, 0.1 $\%$ ) and a pinch of Nitrate Reagent C (Zinc dust). Colour change was examined for resistance while no colour change for sensitive.

\section{GC-MS Analysis}

Constituents in the hexane extracts and hexane fractions of the plant were elucidated using GCMS performed on Agilent Technologies 7890 A GC coupled with Agilent Technologies 5975 C MS. Helium was used as carrier gas and sample was injected in split less mode at $70 \mathrm{ev}$ in a column HP 5 MS, length 30 meters, internal diameters $0.320 \mathrm{~mm}$, column thickness $0.25 \mu \mathrm{m}$. The initial temperature was $50^{\circ} \mathrm{C}$, held for 2 minutes, flow rate $10^{\circ} / \mathrm{min}$, final temperature $240^{\circ}$ $\mathrm{C}$, held for 6 minutes. The resulting GC-MS was analyzed using commercially available standards.

\section{Results and Discussion}

Chrysophyllum albidum fruits are sold in local markets in South western Nigeria during December to April. The cotyledonous part of the seeds is roasted, powdered and put in honey for treatment of tuberculosis by traditional practitioners in Abeokuta, Ogun state part of Nigeria. Fractions from the $80 \%$ ethanolic extract were tested for anti-mycobacterium tuberculosis activity. Table 1 below shows that only the hexane fraction was sensitive to the drug susceptible Mycobacterium tuberculosis strains used while the butanol and ethyl acetate fractions did not inhibit the growth of the bacterium.

Table 1: Result of anti-mycobacterium tuberculosis activity of fractions from C. albidum

\begin{tabular}{llcc}
\hline Fractions & Weight & \multicolumn{2}{c}{$\begin{array}{c}\text { Mycobacterium } \\
\text { tuberculosis }\end{array}$} \\
& & PT $_{12}$ & PT $_{10}$ \\
\hline Butanol & $50 \mathrm{mg} / \mathrm{ml}$ & $\mathrm{R}$ & $\mathrm{R}$ \\
Ethylacetate & $10 \mathrm{mg} / \mathrm{ml}$ & $\mathrm{R}$ & $\mathrm{R}$ \\
Hexane & $0.5 \mathrm{mg} / \mathrm{ml}$ & $\mathrm{S}$ & $\mathrm{S}$ \\
Isoniazid & $0.2 \mu \mathrm{g} / \mathrm{ml}$ & $\mathrm{S}$ & $\mathrm{S}$ \\
Rifampicin & $0.4 \mu \mathrm{g} / \mathrm{ml}$ & $\mathrm{S}$ & $\mathrm{S}$
\end{tabular}

Key: $R$ means Resistant (Bacteria growth was not inhibited).

S means Sensitive (Bacteria growth was inhibited).

$\mathrm{PT}_{12}$ Mycobacterium tuberculosis $\mathrm{H}_{37} \mathrm{Rv}$ strain 
$\mathrm{PT}_{10}$ Local isolate of Mycobacterium tuberculosis from TB patient

The seeds were roasted in a closed crucible at three different temperatures, $50^{\circ} \mathrm{C}, 100^{\circ} \mathrm{C}$ and $120^{\circ}$ C. The hexane extracts of the roasted cotyledonous part for $50^{\circ} \mathrm{C}$ and $120^{\circ} \mathrm{C}$ were tested for anti-mycobacterium tuberculosis and the results obtained are shown in Table 2. All the concentrations tested for anti-mycobacterium tuberculosis activity gave positive result, inhibited the growth of the Mycobacterium tuberculosis.

Table 2: Result of anti-mycobacterium tuberculosis activity of Hexane extracts (Roasted seeds)

\begin{tabular}{|c|l|l|c|c|}
\hline S/Ns & Samples tested & Concentrations & \multicolumn{2}{|c|}{ Mycobacterium tuberculosis } \\
\cline { 3 - 5 } & & & $\mathrm{PT}_{12}$ & $\mathrm{PT}_{10}$ \\
\hline \multirow{2}{*}{1.} & Hexane extract $\left(50^{\circ} \mathrm{C}\right)$ & $2 \mathrm{mg} / \mathrm{ml}$ & $\mathrm{S}$ & $\mathrm{S}$ \\
\cline { 3 - 5 } & & $1.5 \mathrm{mg} / \mathrm{l}$ & $\mathrm{S}$ & $\mathrm{S}$ \\
\cline { 3 - 5 } & & $0.4 \mathrm{mg} / \mathrm{ml}$ & $\mathrm{S}$ & $\mathrm{S}$ \\
\hline 2. & Hexane extract $\left(120^{\circ} \mathrm{C}\right)$ & $2 \mathrm{mg} / \mathrm{ml}$ & $\mathrm{S}$ & $\mathrm{S}$ \\
\cline { 3 - 5 } & & $1.5 \mathrm{mg} / \mathrm{ml}$ & $\mathrm{S}$ & $\mathrm{S}$ \\
\cline { 3 - 5 } & & $0.4 \mathrm{mg} / \mathrm{ml}$ & $\mathrm{S}$ & $\mathrm{S}$ \\
\hline 3. & Rifampicin & $0.4 \mu \mathrm{g} / \mathrm{ml}$ & - & $\mathrm{R}$ \\
\hline 4. & Positive control & Agar inoculated only & $\mathrm{R}$ & - \\
\hline 5. & Negative Control & Agar not inoculated & $\mathrm{S}$ & \\
\hline
\end{tabular}

GC-MS analysis was carried out for the antimycobacterium tuberculosis fractions and extracts. Figure 1 shows the chromatogram of the active hexane fraction while figures 2, 3 and 4 are the chromatograms of the hexane extracts for the seeds roasted at $50^{\circ} \mathrm{C}, 100^{\circ} \mathrm{C}$ and $120^{\circ} \mathrm{C}$ respectively. Figure 5 showed structures of some compounds identified by the GC-MS analysis.

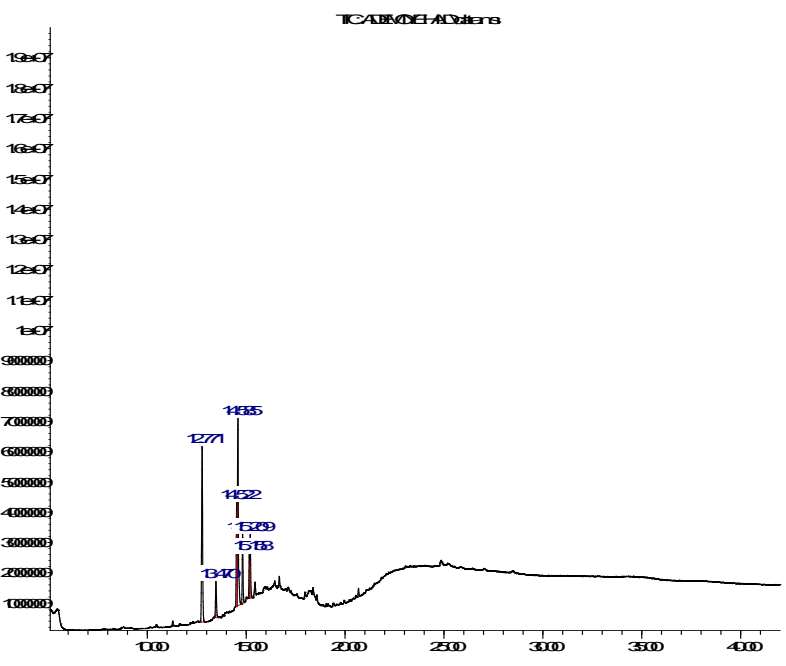

Fig 1: Hexane fraction of C. albidum

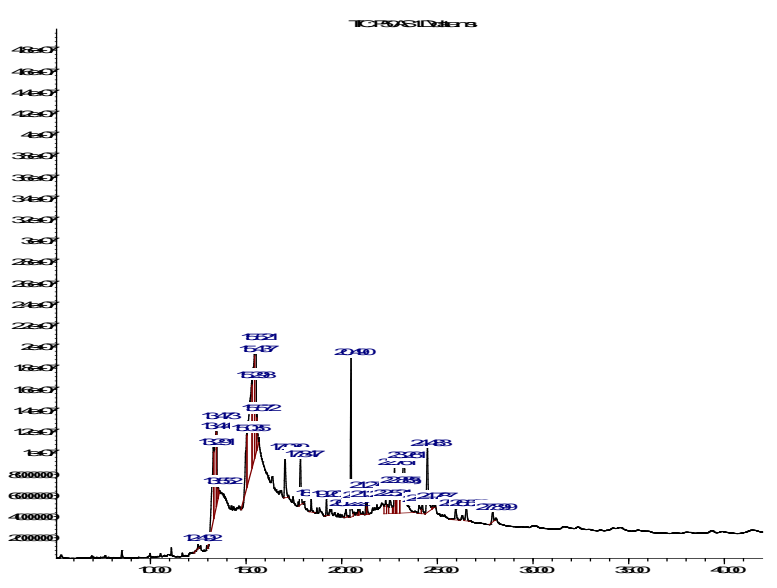

Fig 2: Hexane extract $\mathrm{C}$. albidum roasted seeds $50 \mathrm{deg}$

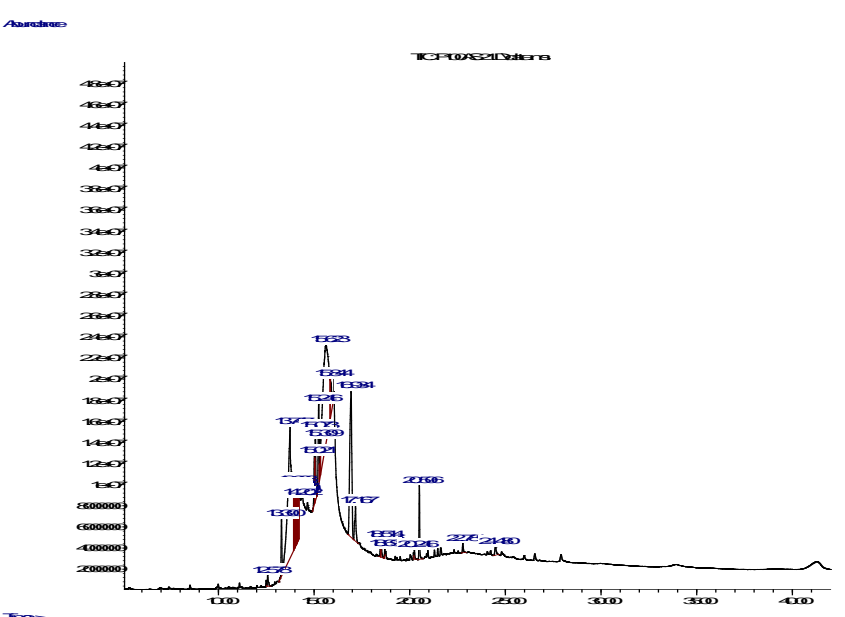

Fig 3: Hexane extract $\mathrm{C}$. albidum roasted seeds 100 deg 


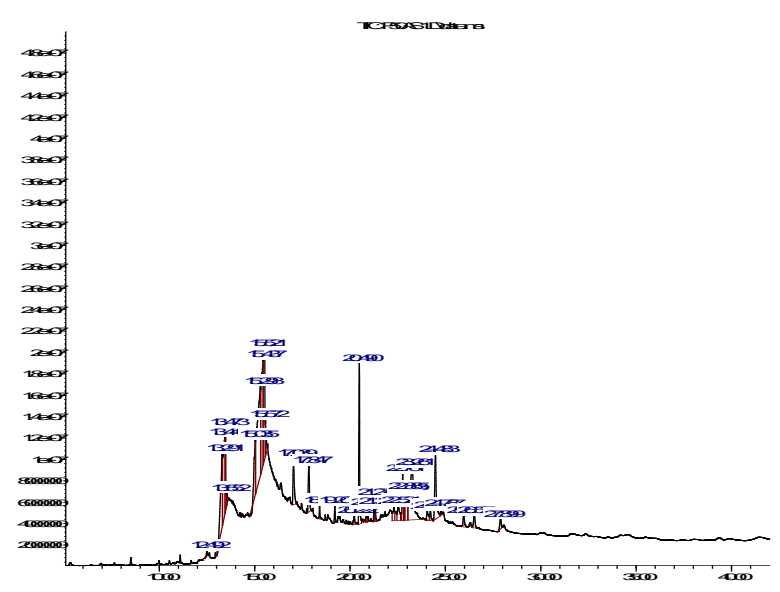

Fig: 4 Hexane extract $C$. albidum roasted seeds $120 \mathrm{deg}$

Esters of long chain saturated and unsaturated fatty acids constituted $92.76 \%$ of the total constituents of the hexane fraction. The methyl ester of unsaturated fatty acids constituted 43.86 \% (11-Octadecenoic acid methyl ester $28.47 \%$ and 9,12-Octadecadienoic acid methyl ester 14.39 $\%)$. The ethyl ester of unsaturated fatty acid is $4.99 \%$ (Linoleic acid ethyl ester). The methyl ester of saturated fatty acids constituted $39.31 \%$ (Hexadecanoic acid methyl ester $30.01 \%$ and Octadecanoic acid methyl ester $9.30 \%$ ). The ethyl ester of satuirated fatty acid is $5.60 \%$ (Hexadecanoic acid ethyl ester). This analysis shows that the methyl esters of unsaturated fatty acids are more than the methyl esters of the saturated fatty acids. Again, the methyl esters of both saturated and unsaturated fatty acids are more than the ethyl esters of the fatty acids.

Fatty acids and their derivatives had been reported as antimicrobial agents (Kabara, 1972).

Table 3: Hexane fraction from C. albidum

\begin{tabular}{|c|l|c|c|}
\hline S/N & Compound & RT & $\%$ \\
\hline 1. & Hexadecanoic acid methyl ester & 12.771 & 30.01 \\
\hline 2. & Hexadecanoic acid ethyl ester & 13.470 & 5.60 \\
\hline 3. & 9,12 -octadecadienoic acid methyl ester & 14.522 & 14.39 \\
\hline 4. & 11-Octadecenoic acid, methyl ester & 14.585 & 28.47 \\
\hline 5. & Octadecanoic acid, methyl ester & 14.814 & 9.30 \\
\hline 6. & Linoleic acid ethyl ester & 15.158 & 4.99 \\
\hline 7. & 1-Nonadecene & 15.209 & 7,29 \\
\hline
\end{tabular}

The GC-MS analysis of the hexane extract of the roasted seeds at $50{ }^{\circ} \mathrm{C}$ showed the presence of long chain fatty acids in high concentration compared to the hexane fraction that showed only the esters of the fatty acids. Again, more compounds were identified in the hexane extract, eighteen compounds compared to only seven compounds identified in the hexane fraction. The dienoic acids, 9,12-Octadecadienoic acid, constituted the highest percentage, $47.85 \%$. This is followed by a saturated fatty acid, nHexadecanoic acid $17.46 \%$. The third fatty acid identified is the monoenoic acid, oleic acid 3.38 $\%$. Polyunsaturated fatty acids had been reported to be bactericidal (Knapp and Melly, 1986).

Table 4: Hexane extract of roasted seeds $\left(50^{\circ} \mathrm{C}\right)$

\begin{tabular}{|c|l|c|c|}
\hline S/N & Compound & RT & $\%$ \\
\hline 1. & Tetracontane & 12491 & 0.18 \\
\hline 2. & n-Hexadecanoic acid & $13.292-13.550$ & 17.46 \\
\hline 3. & $9,12-$ Octadecadienoic acid (Z,Z) & $15.037-15.570,23.250$ & 47.85 \\
\hline 4. & Oleic acid & $17.040,18.408$ & 3.38 \\
\hline 5. & $9,17-O c t a d e c a d i e n a l ~(Z)$ & 17.847 & 2.73 \\
\hline 6. & 2-methyl-Z,Z-3,13-Octadecadienol & $19.209,24.785$ & 0.97 \\
\hline 7. & Z,E-2,13-Octadecadien-1-ol & $20.222,24.050$ & 1.27 \\
\hline 8. & 2,6,10,14,18,22-Tetracoshexaene-2,6,10,15,19,23- & 20.491 & 6.51 \\
\hline
\end{tabular}




\begin{tabular}{|c|l|c|c|}
\hline & hexamethyl- (all E) & & \\
\hline 9. & 11,13-Dimethyl-12-tetradecen-1-ol acetate & $20.857,22.522$ & 2.03 \\
\hline 10. & Cis-Vaccinic acid & 20.925 & 0.56 \\
\hline 11. & Farnesol isomer a & 21.269 & 0.84 \\
\hline 12. & 5,9,13-Pentadecatrien-2-one,6,1014-trimethyl (E,E) & 21.326 & 0.56 \\
\hline 13. & Z,E-3,13-Octadecadien-1-ol & $22.299,24.210$ & 1.73 \\
\hline 14. & Vitamin E & 22.762 & 2.296 \\
\hline 15. & 9-Octadecyne & 22.859 & 4.04 \\
\hline 16. & Stigmasta-7,16-dien-3-ol(3. Beta.,5.alpha) & 24.484 & 5.03 \\
\hline 17. & 2(1H)-Naphthalenone,octahydro-4a-methyl-7-(1- & $25.96,26.521$ & 1.93 \\
\hline 18. & methylethyl)-,(4.alpha.,7.beta.,8a.beta)- & 27.900 & 0.65 \\
\hline
\end{tabular}

Other compounds of biological importance identified in the hexane extract of the seeds roasted at $50^{\circ} \mathrm{C}$ which are individually more than $1 \%$ include a stigmasterol (Stigmasta-7,16-dien3-ol(3.Beta.,5.alpha), Squalene (2,6,10,14,18,22Tetracosahexaene-2,6,10,15,19,23 hexamethyl-), vitamin E, 9-Octadecyne and unsaturated long chain alcohol (Z,E-3,13-Octadecadien-1-ol). A stigmasterol isolated from Knowltonia vesicatoria had been reported to be active against drug sensitive Mycobacterium tuberculosis (Labuschagné et al, 2012), 9-Octadecyne (4.04\%) had been reported to possess good solubility, good inhibition ability, high penetration potential and low binding energy to target protein and thus had been recommended as a drug molecule (Upgade et al, 2014). Squalene, a triterpene and a precursor for synthesis of sterols, has antioxidant, chemopreventive and antitumor activities (Spanova and Drum, 2011; Das et al, 2008). Vitamin $\mathrm{E}$ is antiaging, analgesic, antidiabetic, anti-inflammatory, antioxidant, anticancer (Narayanamoorthi et al, 2015).The use of the cotyledonous in treating vagina infections could be due to the presence vitamin E. The 2,13Octadecadien-1-ol and the 3,13-Octadecadien-1-ol are pheromones (Naka et al, 2006).

Table 5: Hexane extracts of roasted seeds $\left(100^{\circ} \mathrm{C}\right)$

\begin{tabular}{|c|c|c|c|}
\hline $\mathrm{S} / \mathrm{N}$ & Compound & RT & $\%$ \\
\hline 1. & Hexadecanoic acid, methyl ester & 12.577 & 0.54 \\
\hline 2. & Hexadecanoic acid, ethyl ester & 13.298 & 2.31 \\
\hline 3. & n-Hexadecanoic acid & $13.750-15.312$ & 41.98 \\
\hline 4. & 9,12-OCtadecadienoic acid ethyl ester & 15.020 & 1.62 \\
\hline 5. & Ethyl oleate & 15.072 & 2.82 \\
\hline 6. & 9,12-Octadecadienoic acid $(\mathrm{Z}, \mathrm{Z})$ & $15.621,15.844$ & 29.91 \\
\hline 7. & 9-Octadecenal (Z)- & 16.931 & 13.61 \\
\hline 8. & Cis-13-Octadecenoic acid & $17.166,24.478$ & 2.65 \\
\hline 9. & 9-Octadecenoic acid (E) & 18.470 & 0.45 \\
\hline 10. & cis-10-Heptadecenoic acid & 18.516 & 0.73 \\
\hline 11. & Z,E-2,13-Octadecadien-1-ol & 18.699 & 0.17 \\
\hline 12. & 3-Eicosene & 20.244 & 0.30 \\
\hline 13. & 2,6,10,14,18,22-Tetracosahexaene,2,6,10,15,19,23-hexamethyl-(all E)- & 20.507 & 2.48 \\
\hline 14. & Vitamin E & 22.779 & 0.41 \\
\hline
\end{tabular}

The GC-MS analysis of the hexane extract of the seeds roasted to $100^{\circ} \mathrm{C}$ showed the fatty acids to be the main constituents as similar to that of $50^{\circ} \mathrm{C}$ roasted seeds. However, there was an increase from $68.69 \%$ of fatty acids in $50^{\circ} \mathrm{C}$ to $71.89 \%$ in $100^{\circ} \mathrm{C}$. The GC-MS analysis of the hexane extract 
of that of $120^{\circ} \mathrm{C}$ showed the highest concentration of the fatty acids with $92.19 \%$. Other compounds with more than $1 \%$ percentage abundance are 9,17-Octadecadiena $2.44 \%$ and squalene $1.52 \%$. The two main fatty acids that had been consistent in all the roasted seeds extraction are Hexadecanoic acids and 9,12-Octadecadienoic acid. Unsaturated fatty acids inhibited growth of methicillin-resistant staphylococcus aureus (Ohta et al, 1995). Fatty acids had been characterized in the anti-tuberculosis activity of ink extracts of cuttlefish, sepiella inermis (Ravitchandirane et al, 2013). The antitubercular activity of the fixed oil of Moringa oleifera seed had been attributed to the oleic acid and palmitic acid (Egharevba et al, 2015). Unsaturated fatty acids had been reported to kill Mycobacterium in a short time (Kanetsuna, 1985).

Table 6: Hexane extract of roasted seeds $\left(120^{\circ} \mathrm{C}\right)$

\begin{tabular}{|c|c|c|c|}
\hline $\mathrm{S} / \mathrm{N}$ & Compounds & RT & $\%$ \\
\hline 1. & Octacosane & 12.949 & 0.10 \\
\hline 2. & Hexadecanoic acid ethyl ester & 13.298 & 0.65 \\
\hline 3. & Hexadecanoic acid & $13.859-15.341$ & 42.24 \\
\hline 4. & 9,12-Octadecadienoic acid (E,E)- & $15.644-16.090$ & 49.41 \\
\hline 5. & 9,17-Octadecadienal & 15.924-16.067 & 2.44 \\
\hline 6. & trans-13-Octadecenoic acid & 17.183 & 0.54 \\
\hline 7. & Cyclohexane,1,3-dimethoxy-,cis & 17.767 & 0.17 \\
\hline 8. & 9-Octadecenoic acid (E)- & 18.471 & 0.18 \\
\hline 9. & 4-(3,4,,5,6-Tetrahydroxy-2-oxo-hexylamino-)-benzonitrile & 19.255 & 0.26 \\
\hline 10 . & 2,6,10,14,18,22-Tetracosahexaene,2,6,10,15,9,23-hexamethyl-(all E)- & 20.519 & 1.52 \\
\hline 11. & 11,13-Dimethyl-12-tetradecen-1-ol acetate & 20.891 & 0.10 \\
\hline 12. & Hexadecane, 1-iodo & 20.954 & 0.12 \\
\hline 13. & $\begin{array}{l}\text { Cyclopropane carboxamide, 2-cyclopropyl-2-methyl-N-(1- } \\
\text { cyclopropylethyl)- }\end{array}$ & 21.297 & 0.17 \\
\hline 14. & Vitamin E & 22.779 & 0.40 \\
\hline 15. & Z,E-2,13-Octadecadien-1-ol & 24.067 & 0.21 \\
\hline 16. & 1-Cyclohexylnonene & 24.233 & 0.29 \\
\hline 17. & Ergosta-14,22-dien-3-ol,(3.beta.,5.alpha.,22E)- & 24.496 & 0.59 \\
\hline 18. & Cis-11,12-Epoxytetradecen-1-ol & 24.811 & 0.16 \\
\hline 19. & 7-Pentadecyne & 25.544 & 0.21 \\
\hline 20. & Pregnan-20-one-3,11-dihydroxy-3.beta.,5.alpha.,11.alpha- & 27.918 & 0.26 \\
\hline
\end{tabular}

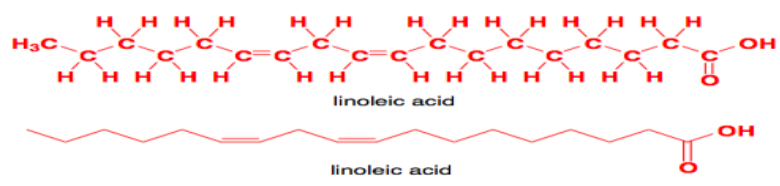

Linoleic acid- Antidiabetic-Hepatoprotective

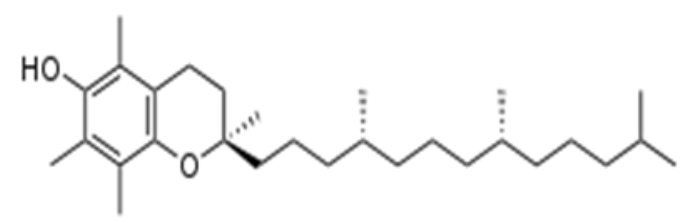

Vaginal lubrication, Anti-aging<smiles>CC(C)(C)CCCCCC(=O)O</smiles>

n-Hexadecanoic acid-Anti-inflammatory

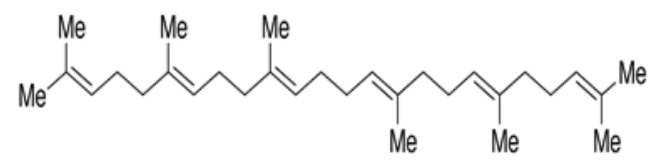

Squalene- Antitumor 


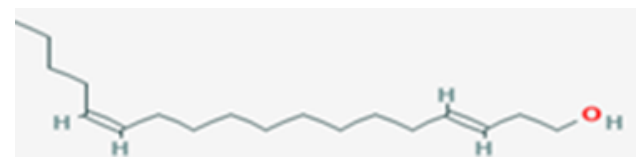

Z,E-3,13-Octadecadien-1-ol - a pheromone

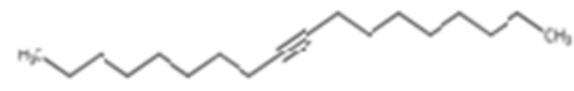

9-Octadecyne

Figure 5: Structures of some compounds identified

It is possible that the saturated fatty acid, Hexadecanoic acid, work together with the unsaturated fatty acid to inhibit the growth of the Mycobacterium tuberculosis. The Hexadecanoic acid is anti-inflammatory, inhibiting the activity of phospholipase A2 (Aparna et al, 2002) and thereby possibly enhancing the activity of 9,12Octadecadienoic acid in binding to Fatty acid synthase. Non-steroidal anti-inflammatory drugs had been reported to sensitize Mycobacterium tuberculosis to endogenous and exogenous antimicrobials (Gold et al, 2012). Also in line with this is a report that Aspirin and Ibuprofin enhance pyrazinamide treatment of murine tuberculosis (Byrne et al, 2007). The probable mechanism of mycobactericidal effect of the 9,12Octadecadienoic acid in binding to the Fatty acid synthase had been reported (Weaks and Wakil, 1970). Pyrazinoic acid inhibits fatty acid synthase type 1 in replicating tubercle bacilli (Zimhony et al, 2007). A collaboration action among fatty acids and other antimicrobial effectors to bring about macrophage-mediated killing of mycobacterium had been suggested (Akaki et al, 1997). It could also be suggested that the fatty acids get involved in lipid peroxidation which in turn increases the toxicity of hydrogen peroxide (Sheridan et al, 1996). The hydrogen peroxide toxicity contributes to tuberculocidal effect especially if the whole process is accompanied with decline $\mathrm{pH}$ (Jackett et al, 1978). Thus, the anti-mycobacterium tuberculosis activity of the cotyledonous part of the seeds of Chrysophyllum albidum is due to its saturated and unsaturated fatty acids which seem to work synergistically to bring about the anti-tubercular activity. The method of roasting of the seeds by traditional practitioners also ensure the availability of the active ingredients, the saturated and the unsaturated fatty acids, in high concentration as implied in the GC-MS analysis of the 120 o C roasted seeds.

\section{Conclusion}

The anti-mycobacterium tuberculosis property of the white cotyledonous part of Chrysophyllum albidum had been scientifically validated. The anti-tubercular activity of the seeds could be attributed to the presence of Hexadecanoic acid and 9,12-Octadecadienoic acid.

The GC-MS analysis of the raw seeds compared with that of the roasted seeds showed that the raw seeds contained $92.71 \%$ of fatty acid ester while the roasted seeds contained the free fatty acids in increasing concentration as the temperature increases (Free fatty acids: $68.69 \%$ at $50 \mathrm{deg}$, $74.54 \%$ at $100 \mathrm{deg}$ and $91.65 \%$ at $120 \mathrm{deg}$ ). Thus, the traditional method of using the roasted seeds of Chrysophyllum albidum in treating tuberculosis enhances the availability of the free fatty acids in high concentration for the antimycobacterium tuberculosis effect.

\section{Conflict of Interest}

The authors declare no conflict of interest.

\section{Acknowledgement}

We sincerely acknowledge the Nigerian Institute of Medical Research, NIMR, Yaba, for granting us permission to use their tuberculosis laboratory facilities. Our sincere gratitude goes to $\mathrm{Mr}$ Nshiogu Michael, a member of staff of NIMR, for his technical assistance.

\section{References}

[1] H. A. Adebayo, and Abolaji, Amos Olalekan and Kela, Roseline and Oluremi, Samuel Oluwabiyi and Owolabi, Olumide Oluwatosin and Ogungbe, Oluwaseun 
Afolabi (2011) Hepatoprotective activity of Chrysophyllum albidum against carbon tetrachloride induced hepatic damage in rats. Canadian Journal of Pure and Applied Sciences, 5 (3). pp. 1597-1602. ISSN 1920-3853

[2] I. Adeleye, C. C. Onubogu, C. I. Ayolabi, A. O. Isawumi and M. E. Nshiogu. (2008) Screening of twelve medicinal plants and 'wonder-cure' concoction used in Nigeria unorthodox medicine for activity against Mycobacterium tuberculosis patients sputum. African Journal of Biotechnology vol. 7 (18): 3182-3187 ISSN 1684-5315

[3] E. O. Adewoye, A. T. Salami and V. O. Taiwo (2010). Anti-plasmodial and toxicological effects of methanolic bark extract of Chrysophyllum albidum in albino mice. Journal of Physiology and Pathophysiology Volume 1 (1) pp 1-9.

[4] S. A. Adisa 2000. Vitamin C, protein and mineral content of African apple (Chrysophyllum albidum) in proceedings of the 18th Annual Conference of the National Institute of Standards and Technology (NIST) (Eds), 141-146.

[5] T. Akaki, K. Sato, T. Shimizu, H. Kajitani, S Dekio, H. Tomioka (1997). Effector molecules in expression of the antimicrobial activity of macrophages against Mycobacterium avium complex: roles of reactive nitrogen intermediates, reactive oxygen intermediates and free fatty acids. Journal of Leukocyte Biololy. Vol. 62 (6): 795-804.

[6] V. Aparna, K. V. Dileep, P. K. Mandal, P. Karthe, C. Sadasivan, M. Haridas (2002) Anti-inflammatory property of nhexadecanoic acid: structural evidence and kinetic assessment; Chemical Biololy \$ Drug Design 80 (3): 434-439. doi: 10.1111/j.1747-0285.2012.01418.x.

[7] S. T. Byrne, S. M. Denkim and Y. Zhang (2007). Aspirin and Ibuprofen enhance pyrazinamide treatment of murine tuberculosis. The Journal of Antimicrobial
Chemotherapy, Vol. 59 Issue No 2 pp 313316. DOI: $10.1093 / \mathrm{jac} / \mathrm{dk1} 486$

[8] S. A. Cantrell, M. D. Leavell, O. Marjanovic, A. T. Iavanone, J. A. Leary, W. Riley (2013). Free mycolic acid accumulation in the cell wall of the mce 1 operon mutant strain of Mycobacterium tuberculosis. Journal of Microbiology 51 (5): 619-626.

[9] B. Das, R. Antoon, P. Tsuchida, S. Lofti, O. Mirozora, W. Farhat et al (2008). Squalene selectively protects mouse bone marrow progenitors against cisplatin and carboplatin - induced cytotoxicity in vivo without protecting tumor growth. Neoplasia 10 (10): 1105-1119.

[10] H. O. Egharevba, P. Oladosu, K. S. Izebe, and O. F. Kunle (2015). Chemical composition and antitubercular activity of the fixed oil of Moringa oleifera seed . Journal of Chemical and Pharmaceutical Research 7 (12): 412-418

[11] B. Florence, and A. H. Adiaha (2015) Storage effects and the post harvest quality of African star apple fruits (Chrysophyllum africanum ) under ambient conditions. African Journal of Food Science and Technology, vol. 6 (1): 35-43.

[12] Gold, M. Pingle,S. J. Brickner, N. Shah, J. Roberts, M. Rundell, W. C. Bracken, T. Warrier, S. Somersen, A. Venugopal, C. Darby, X. Jiang, J. D. Warren, J. Fernandez, O. Ouerfelli et al, 2012, Non steroidal anti-inflammatory drug sensitizes Mycobacterium tuberculosis to endogenous and exogenous antimicrobials, Proceedings of the National Academy of Sciences USA 109 (40) : 16004-11. Doi : 10.1073/pnas 1214188109.

[13] P. S. Jackett, V. R. Aber and D. B. Lowrie (1978) Virulence and Resistance to Superoxide, Low $\mathrm{pH}$ and Hydrogen Peroxide among Strains of Mycobacterium tuberculosis. Journal of General Microbiology. 104, 37-45. 
[14] J. J. Kabara, D. M. Swieczkowski, A. J. Conley, J. P. Truant (1972) Fatty Acids and Derivatives as Antimicrobial Agents. Antimicrobial Agents and Chemotherapy. ;2(1):23-28.

[15] F. Kanetsuna (1985) Bactericidal effect of fatty acids on Mycobacteria, with particular reference to suggested mechanism of intracellular killing. Microbiology and Immunology Vol. 29 (2):127-141

[16] H. R. Knapp and M. A. Melly (1986) Bactericidal effects of polyunsaturated fatty acids. The Journal of Infectious Diseases. Volume 154 Issue 1 pp 84-94.

[17] Labuschagné, A. A. Hussein, B Rodríguez and N. Lall (2012) Synergistic Antimycobacterial Actions of Knowltonia vesicatoria (L.f) Sims. Evidence-Based Complementary and Alternative Medicine Volume 2012, Article ID 808979, 9 pages http://dx.doi.org/10.1155/2012/808979

[18] BY Lee, DL Clemens, A Silva, BJ Dillon, S Masleša-Galić, S Nava, X Ding, CM Ho, and MA Horwitz (2017) Drug regimens identified and optimized by output-driven platform markedly reduce tuberculosis treatment time. Nature Communication 8: 14183 DOI: 10.1038/ncomms14183.

[19] I.Mac Donald, O. O. Nosa, O. O. Emmanuel and O. E. Joseph 2014. Phytochemical and antimicrobial properties of Chrysophyllum albidum Dacryodes edulis, Garcinia kola chloroform and ethanolic root extracts.Journal of Intercultural Ethnopharmacology 3 (1): 15-20.

[20] L. S. Meena and Rajni, 2010, Survival mechanism of pathogenic Mycobacterium tuberculosis H37Rv, The Federation of European Biochemical Societies (FEBS) Journal volume 277 issue 11 pp 24162427. Doi:10.1111/j.17424658.2010.07666.x.

[21] P. Mehrotra, S. V. Jamwal, N. Saquib, N. Sinha, Z. Siddiqui, V. Manivel et al. (2014) Pathogenicity of Mycobacterium tuberculosis Is Expressed by Regulating Metabolic Thresholds of the Host Macrophage. PLOS Pathogens 10(7): e1004265.

https://doi.org/10.1371/journal.ppat.10042 65

[22] H. Naka, T. Nakazawa, M. Sugie, M. Yamamoto, Y. Horie, R. Wakasugi, Y. Arita, H. Sugie (2006). Synthesis and characterization of 3,13- and 2,13Octadeadienyl compounds for identification of the sex pheromone secreted by Clearwingmoth, Nokona premix. Bioscience, Biotechnology, and Biochemistry 70 (2): 508-516.

[23] V. Narayanamoorthi, K. Vasantha, R. C. Rency and A. Maruthasalam (2015). GCMS determination of bioactive components of Peperomia pellucid (L.) Kunth. Bioscience Discovery 6 (2): 83-88.

[24] O. Oboh, E. O. Aluyor and T. O. K. Audu 2009. Use of Chrysophyllum albidum for the removal of metal ions from aqueous solutions. Scientific Research and Essay, vol. 4 (6): 632-635.

[25] D. S. Olorunnisola, I. S. Amao, D. O. Ehigie and Z. A. Ajayi 2008. AntiHyperglycemic and Hypolipdemic Effect of Ethanolic Extract of Chrysophyllum albidum seed cotyledon in Alloxan Induced-Diabetic Rats. Research Journal of Applied Sciences vol. 3 Issue 2: 123 127.

http://medwelljournals.com/abstract/?doi= rjasci.2008.123.127

[26] S. Ohta, Y. Shiomi, A. Kawashima, O. Aozasa, T. Nakao, T. Nagate, K. Kitamura and H. Miyata (1995) Antibiotic effect of linolenic acid from Chlorococcum strain HS-101 and Dunaliella primolecta on methicillin-resistant Staphylococcus aureus. Journal of Applied Physiology. Volume 7 Issue 2 pages 121-127. https://doi.org/10.1007/BF00693057

[27] C. Onyeka, A. U. Aligwekwe, T. S. Olawuyi, A. A. Nwakauma, E. C. Kalu, A. W. Oyeyemi (2012). Antifertility 
effects of ethanolic root bark extract of Chrysophyllum albidum in male Albino rats. International Journal of Applied Research in Natural Products. Volume 5 number 1 pp 12-17.

[28] J. Pieters (2008) Mycobacterium tuberculosis and the macrophage: Maintaining a balance, Cell Host \& Microbe, volume 3 issue 6 pp. 399-407.

[29] R. Prasad, A. Singh,V. Balasubramanian and N. Gupta 2017, Extensively drugresistant tuberculosis in India : current evidence on diagnosis \& management. Indian Journal of Medical Research 145 (3) : 271-293. Doi : 10.4103/ijmr.IJMR 17716 PMC 5555056.

[30] C. J. Queval, O-R Song, J-P Carralot et al. (2013). Mycobacterium tuberculosis Controls Phagosomal Acidification by Targeting CISH-Mediated Signaling. Cell Reports. $\quad 20 \quad$ (13):3188-3198. doi:10.1016/j.celrep.2017.08.101.

[31] M. Ravichandiran, S. Thiripurasalmi, V. Ravitchandirane, S. Goplane and C. Stella 2013 Chemical constituents and antiyuberculosis activity of ink extracts of cuttle fish, sepiella inermis, Journal of Coastal Life Medicine 1 (4): 273-277. Doi : 10.12980/JCLM.1.2013.957.

[32] C. Rousseau, N. Winter, E. Pivert and M. Jackson (2004) Production of phthiocerol dimycocerosates protects Mycobacterium tuberculosis from the cidal activity of reactive nitrogen intermediates produced by macrophages and modulates early immune response to infection. Cellular Microbiology 6 (3): 277-287. Doi : 10.1046/j.1462-5822.2004.00368.x

[33] K. Salami and P. O. Oluboye, (2002) Hospital prevalence of pulmonary tuberculosis and co-infection with HumanImmuno Deficiency virus in Ilorin: a review of nine years (1991-1999), West African Journal of Medicine. 4 : 24-27

[34] M. Sheridan, S. Fitzpatrick, C. Wang, D. C. Wheeler and W. Lieberthal (1996) Lipid peroxidation contributes to hydrogen peroxide induced cytotoxicity in renal epithelial cells. Kidney International 49 (1): 88-93.

[35] M. Spanova and G. Drum (2011) Squalene - biochemistry, molecular biology,pressbiotechnology and applications. European Journal of Lipid Science and Technology. 113 (11): 12991320.

[36] Z. Toosi (2000). The inflammatory response in Mycobacterium tuberculosis infection. Archivum Immunologiae et Therapia Experimentalis (Warsz) 48 (5): 513-519.

[37] Upgade, A. Bhaskar and P. Kumarasamyi 2014, Evaluation of natural compound as a potential drug against DENV non structural proteins: In silico study, Asian Journal of Biochemistry $9: 131-141$

[38] G. Weaks and S. J. Wakil (1970) Studies on the control of fatty acid metabolism. II The inhibition of fatty acid synthase in Lactobacillus plantarum by exogenous fatty acid. The Journal of Biological Chemistry vol 245 No 8 pp 1913-1921

[39] World Health Organization, WHO Traditional Medicine Strategy 2002-2005, World Health Organization, Geneva, Switzerland, 2002

[40] O. Zimhony, C. Vilchèze, M. Arai, J. T. Welch and W. R. Jacobs Jr. (2007). Pyrazinoic acid and its n-propyl ester inhibit fatty acid synthase type 1 in replicating tubercle bacilli. Antimicrobial Agents and Chemotherapy 51 (2): 752-754 